\title{
The Vicky Calder Case: A Review
}

\section{Wornes DJ ${ }^{*}$}

School of Veterinary and Life Sciences, Murdoch University, Perth, Australia

${ }^{*}$ Corresponding author: Wornes DJ, School of Veterinary and Life Sciences, Murdoch University, Perth, Australia, E-mail: danielle.wornes@icloud.com

Citation: Wornes DJ (2016) The Vicky Calder Case: A Review. J Forensic Sci Criminol 4(1): 103. doi: 10.15744/2348-9804.4.103

\section{Received Date: August 29, 2015 Accepted Date: February 24, 2016 Published Date: February 25, 2016}

\begin{abstract}
Vicky Calder stood trial twice for the attempted murder of her ex-de facto partner, David Lloyd, by means of deliberate poisoning with acrylamide. Lloyd was left blind, paralysed from the neck down and was unable to speak without mechanical assistance after he fell into a coma following a mysterious ailment. Calder's first trial resulted in a hung jury, while the second obtained a notguilty verdict. The case was largely built on circumstantial evidence and subsequently relied heavily on chemical evidence and scientific expertise for the detection of acrylamide exposure in hair and blood samples taken from Lloyd 3 weeks after he fell ill. Forensic experts detected CEC levels that were up to 100 times higher ( 500 micrograms of CEC per gram of hair) when compared to individuals that had been exposed to acrylamide and similar intensive care drugs that Lloyd had been exposed to Experts also prepared segmental analysis of Lloyd's hair samples, which showed a peak acrylamide concentration in a band of the hair that corresponded to when Lloyd fell ill. Additionally, Lloyd's blood samples were found to contain 800 times more CEV than a group of healthy normal individuals. Considering these astounding statistics, it is apparent that Calder's acquittal was due to a number of difficulties that the prosecution faced in court. This paper will explore the complications associated with hair analysis and the detection methods used for acrylamide; the significance of the Daubert principle; the difficulties encountered by juries in cases that revolve around complex scientific evidence and the various toxicokinetic and toxicodynamic principles of acrylamide. Recommendations have also been made with regards to dealing with similar cases in the future.
\end{abstract}

Keywords: Acrylamide; Poisoning; Case review; Hair analysis; Toxicokinetics; Toxicodynamics; Daubert principle

\section{Background}

David Lloyd, at 55 years old was a Professor of plant biology at the University of Canterbury. He lived with his de facto partner of approximately 6 years, Vicky Calder in Christchurch, New Zealand. Calder was a 43-year-old molecular biologist at the Christchurch medical school. In June 1992, Lloyd and Calder both travelled to London for Lloyd to receive a Fellowship of the Royal Society. They subsequently holidayed in Italy for 10 days and parted ways following the vacation. Lloyd travelled to Berkley, California for a conference, while Calder went to Amsterdam for a meeting. In California Lloyd met with Linda Newstrom. Lloyd had previously met Newstrom, who was at the time a research associate specialising in botany at the University of California in Berkley, in November 1990, where he had passed through campus as a visiting professor. They shared professional interests and developed a friendship. One month after he had left California in 1990, Lloyd pursued Newstrom romantically, but to no avail. During the second visit in June 1992 the romantic interest on Lloyd's behalf continued; Newstrom also divulged her feelings which left Lloyd determined to leave Calder to be with Newstrom [1].

Lloyd returned to Christchurch on June $28^{\text {th }}$. Calder had already returned from Amsterdam and picked him up from the airport in the presence of her sons and her parents. As soon as he was alone with Calder he revealed that he had met another woman and wanted to spend the rest of his life with her. Six days after leaving Berkley, Lloyd had notified Newstrom that he had left Calder and had already moved into his own flat. Calder did not take the news lightly. Her anger was expressed by writing numerous letters to Lloyd indicating her disapproval of the situation he had put her in, she let down the tyres of Lloyds car, erected resentful signs on his windshield in the university car park and cut up his shirts and trousers that were still in her wardrobe. A few months after the break-up Calder sent Newstrom a letter including photos of Calder and Lloyd. Additionally, Newstrom received an odd letter from an individual who identified herself as 'Salia, who was unknown to Newstrom, accusing her of being a terrible person to break up Calder and Lloyd's relationship: it was later revealed that Calder had been responsible for this letter, along with a 'love letter' and postcard written to Lloyd from a 'Sarah Mills' [1]. 
On December $13^{\text {th }}$ Lloyd's daughter, Nicola Marriott-Lloyd, phoned Lloyd. He told her that he had been vomiting, believing it to be food poisoning from a dinner he hosted on December $11^{\text {th }}$. The vomiting continued through December $14^{\text {th }}$ when he told Newstrom the same information, who was due to leave California for Christchurch in approximately a week. His condition deteriorated and on December $17^{\text {th }}$ Constable Jeanie McCormick found him incoherent, unsteady and slurring his speech after he reported a burglar in his flat to the police. A work colleague, Gerald Cuthbert, found him at home in a delirious state on December $18^{\text {th }}$; he was stumbling, sweating profusely and slurring his words. Cuthbert took Lloyd firstly to see his general practitioner, Michael Foster. Lloyd had a genetic enzyme deficiency, alpha 1 antitrypsin, which can lead to liver cirrhosis and lung deterioration, so Foster was familiar with Lloyd. Foster was shocked at his appearance and recommended that he go to hospital. Calder visited Lloyd in hospital later that evening to find him hallucinating. Later that day he was unable to speak, hours later he was in a coma $[1]$.

Detective Sergeant Rob Pope was notified by Christchurch Hospital of a suspicious incident on January $3^{\text {rd }} 1993$, this being the alleged attempted murder of Lloyd by means of deliberate poisoning. The alleged poison was later purported to be a member of the acrylic family and subsequent tests focussed on acrylamide as the suspect agent. Lloyd regained consciousness in April 1993, but was left blind, paralysed from the neck down and was unable to speak without mechanical assistance [2].

On June $6^{\text {th }} 1994$ Calder was arrested and charged with the attempted murder of Lloyd. For Calder to be convicted by a guilty verdict, the prosecution had to prove three propositions; Lloyd's illness was caused by acrylamide, Calder administered it on or around December $12^{\text {th }}$ and that Calder intended to kill or cause grievous bodily harm. The first trial began on September 18,1995 and resulted in a hung jury. The case was put to yet another jury five months later. This second trial found a not-guilty verdict [1,2].

The Vicky Calder case was largely built on circumstantial evidence [2] that eventually led to Calder's arrest and charge with the attempted murder of David Lloyd. Subsequently, the trials heavily relied on the chemical evidence and scientific expertise in the detection for acrylamide exposure in hair and blood samples taken from Lloyd [1]. This review will focus primarily on the difficulties that the prosecution had in proving Calder's guilt involving complications associated with hair analysis and the detection methods used for acrylamide, the significance of the Daubert principle, the difficulties encountered by juries in cases that revolve around complex scientific evidence and the various toxicokinetic and toxicodynamic principles of acrylamide. These contentious points of the case will be discussed at length and will provide a comprehensive review as to the reasons behind Calder's acquittal.

\section{Hair Analysis in Criminal Cases}

\section{Hair Analysis in the Calder Case}

The approach that was adopted by the prosecution in the detection of acrylamide for the first trial in the Calder case was based upon two facts; that in its free state, acrylamide is usually excreted from the circulatory system within 1-2 days of absorption, and, that acrylamide is a highly reactive substance in the body which binds to cysteine to form and adduct, S-carboxyethyl cysteine (CEC). This meant that the blood samples would yield no evidence of free acrylamide in the circulatory system (since the blood samples were taken at least three weeks after he had become ill) and that they had to look for other indicative acrylamide metabolites, i.e. CEC, as a footprint for acrylamide exposure. In the blood CEC exists with red blood cells for approximately three months. Additionally acrylamide reacts with hair to form CEC. This is because the major structural protein of hair is keratin, which contains a large number of cysteine residues. Thus, theoretically both hair and blood could be used to determine acrylamide exposure. The prosecution tested the hair and blood samples that were taken from Lloyd at least 3 weeks after he had become ill, but focussed on hair analysis utilising an untried, novel procedure (the CEC test) [1,2].

Eric Cairns, the prosecutions scientific expert firstly established the presence of CEC and compared it with samples from individuals exposed to acrylamide in their work and some who had received intensive care drugs, similar to Lloyd. Cairns found that the level of CEC in Lloyd's hair was up to 100 times higher than the rest of the group and reached concentrations of more than 500 micrograms of CEC per gram of hair. Cairns then used segmental analysis of Lloyd's hair to plot a 'calendar effect' to determine the point in time at which Lloyd's body was exposed to acrylamide. He determined a peak in CEC levels in the mid-December, which was interpreted to correspond to the onset and progression of Lloyd's illness. The defence discredited the prosecutions evidence, pointing out the novelty of the technique used and the existence of a more specific test for acrylamide, namely the carbamoyl ethyl valine $(\mathrm{CEV})$ test $[1,2]$.

The second trial saw the prosecution adopt the even more recently developed CEV test for acrylamide exposure. They tested the same blood samples taken from Lloyd, which had been stored since the time of the alleged poisoning, for CEV. CEV is formed when acrylamide reacts with the N-terminal amino acid (a valine residue) in haemoglobin, this adduct lasts for up four months in the blood. Lloyd's stored blood was found to contain 800 times more CEV than a group of healthy normal individuals. They also repeated their first test for CEC in the hair and found high levels of the adduct in a band and suggested that Lloyd had ingested the poison over a period of 1-2 weeks. As in the first trial the defence claimed that the evidence was inconclusive and once again revealed another alternative test that was even more specific for the positive identification of acrylamide exposure: the identification of glycidamide a by-product of acrylamide in the liver [1]. 


\section{Difficulties Associated with Hair Analysis in Criminal Cases}

Aside from the numerous legal issues associated with the utilisation of a novel approach to attain forensic evidence, hair analysis itself is fraught with difficulties despite it having various advantages over traditional biological specimens [3] (i.e. blood and urine). Any evidence of drug exposure is essentially erased from blood and urine in a matter of hours-days after their intake, due to the natural metabolic and excretion processes [3]. However the same drug and its metabolites are ultimately incorporated into the keratin structure of the hair, from which it is hardly removed: hair has a larger surveillance window (weeks-months) depending on the length of the shaft [4]. This drug-fixing process leads to a potential chronological trace of drug exposure. Hair analysis boasts non-invasive collection that can be carried out by non-specialised personnel and samples that can be replicated (two different samples that can represent the same time window), which is not possible with blood or urine samples $[3,4]$.

The drawbacks of hair analysis for use as forensic evidence lie within the mechanisms by which drugs are incorporated into hair. It is generally accepted that drugs can enter into hair by three mechanisms: adsorption from the external environment, incorporation into the growing hair shaft from blood supplying the hair follicle and from sweat and sebum [4]. Due to the fact that drug and metabolite ratios in blood differ from those found in hair there is no known correlation between hair concentrations and the administered dose for most drugs, therefore it is not possible to calculate blood or plasma concentrations based on hair results [4]. Drug and metabolite concentrations in hair also differ markedly between individuals receiving the same dose [4]. Additionally, there are many factors that influence drug deposition in hair: hair is not a homogenous matrix and the exact mechanism by which chemicals are bound into hair is not known [4,5]. The degree of drug incorporation into hair depends upon the chemical structure and related properties of the drug (i.e. melanin affinity, lipophilicity and membrane permeability). Various studies have demonstrated that after the same dosage, black hair incorporates a higher concentration of drug than blond hair [4].

Possibly the most discouraging aspect for using hair analysis as forensic evidence involves the possibility of producing falsepositives, whereby the individual is exposed to but does not actively consume the drugs (i.e. external adsorption) [3]. This is especially apparent for professionally exposed, and volatile, substances. Alternatively, false negatives may be produced through strong cosmetic hair treatments (for example, the use of oxidants or highly basic colouring) might damage the keratin structure to release the incorporated substances $[3,5]$. The use of cosmetic products (grease, sprays, and gels) may also interfere with hair analysis [3].

The hair growing process itself may also have profound effects on the forensic evidence produced, especially if sample size is limited. Hair does not grow continually, but in cycles, alternating between periods of growth and quiescence [4]. A follicle that is actively producing hair is said to be in the anagen phase. Head hair in this phase will grow at a rate of approximately $0.22-0.52 \mathrm{~mm}$ per day (0.6-1.4cm/month). After this period, the follicle enters a short transition period (catagen phase) for approximately 2 weeks, where cell division stops and the follicle begins to degenerate. Following the transition phase, the hair follicle enters a resting or quiescent period, the telogen phase, for 10 weeks where the hair shaft stops growing completely and hair growth begins to shut down. Factors such as race, disease states, nutritional deficiencies and age are known to influence both the rate of growth and the length of the quiescent period. As an estimate, on the scalp of an adult approximately $85 \%$ of the hair is in the growing phase and the remaining $15 \%$ is in a resting stage [4].

Difficulties also lie within the lack of standardisation of sampling and extraction and decontamination techniques. Collection procedures for hair analysis for drugs have not been standardised and as of 2014 [3], several decontamination procedures had been published in the scientific literature, but general consensus or uniformity regarding these procedures did not exist. In fact, it is assumed that complete elimination of the externally deposited drug is not achieved even after laborious washing procedures [3,6]. However it has been suggested that to deal with external contamination, newly collected hair specimens can be used to evaluate the reproducibility of the results. Overall hair analysis should not be regarded as an ultimate substitute for blood and/or urine in defining drug exposure, but rather as a source for complimentary and informational evidence [6]. Thus, it can be suggested that even two decades after the Calder trial hair analysis is still a controversial technique in the determination of drug exposure due to the numerous reasons listed above.

\section{Presentation of Evidence in the Courtroom}

\section{Significance of the Daubert Principle Applied to Forensic Evidence in the Calder Case}

Prior to the 1980's, the admissibility of expert evidence in New Zealand (and Australia and England) was typically allowed to go before the trier of fact as long as it was relevant, offered by a qualified expert and did not breech one of the traditionally recognised rules of evidence [7]. It is to be noted that a rule discrediting novel approaches in presenting scientific evidence was not recognised. Since then, a number of admissibility regulations have developed and address the potentially prejudicial outcomes of the presentation of expert scientific evidence.

At the time of the Calder case, there was no direct authority in New Zealand that dealt with the admissibility of novel scientific evidence. Justice Tipping himself, the judge appointed to the Calder trial, developed a test for the admissibility of novel scientific evidence. In the Calder trial he dismissed the use of the general acceptance test, or the Frye test. This test states that the expert testimony is only admissible if the underlying scientific principles have gained general acceptance within the relevant scientific community. The downside to this test is that an expert may be eminently qualified in the relevant field, but their testimony cannot be admitted if it is based on emerging science that had not yet achieved general acceptance [7]. 
Tipping devised the 'Calder test' and although it has not been considered by the Court of Appeal, it was suggested that it was the most suitable approach for establishing the admissibility of scientific evidence at the time. In the Calder trial it provided a flexible test for ensuring that relevant and reliable scientific evidence was admissible, taking into account both scientific validity and policy factors. The decision in Calder has much in common with the Daubert Standard or the Daubert Principle [7]. The significance in essentially adopting the Daubert test in the Calder trial, instead of the Frye test meant that expert testimony did not need to meet the general acceptance standard to be admissible: it could be considered admissible as long as the underlying methodology is shown to be relevant and reliable. The Daubert Principle allows for the introduction of novel, sound science if it can be shown to be reliable, scientifically valid and will assist the trier of fact. In addition to this principle the judge, when evaluating expert testimony must consider four factors [7]:

1. Whether the theory or technique can be and has been tested;

2. Whether the theory or technique has been subjected to peer-review and publication;

3. Whether the theory or technique has a known or potential error rate;

4. Whether the theory or technique has general acceptance within a relevant scientific community.

Some judges strictly require experts to meet all four of the outlined criteria, whereas others consider the factors to be independent of one another and determine which factors (if any) apply.

The scientific methods adopted in the Calder trial (both the CEC and CEV tests) to produce chemical evidence by the prosecution to determine exposure to acrylamide were novel: that is the analytical procedures lacked scientific validation. In a pre-trial application surrounding the first trial, the Court was asked, by the defence, to rule on the admissibility of the results of the determination of CEC using a novel scientific technique [7]. The defence contended that the evidence should be considered unreliable novel scientific evidence, as its prejudicial effects would greatly exceed its probative significance. However, Tipping allowed the presentation of the prosecutorial evidence.

Hugh Rushton, the hair expert for the defence, argued that the main problem in this trial was the use of evidence from analytical procedures that lacked or had not undergone scientific validation [1,2]. Rushton suggested that the scientific evidence should never have been used. The use of the novel, untried hair analysis was indeed an obvious and clear violation of the Daubert Principle. However, since at the time of the Calder case, there was no direct authority in New Zealand that dealt with the admissibility of novel scientific evidence, the decision was up to Tipping, who cleared the evidence as admissible.

\section{Complex and Contradictory Scientific Evidence in the Calder Case}

Post second trial, the Lloyd family questioned the ability of the justice system to cope with complex and contradictory science, of which the Calder trials were riddled with. Calder herself also expressed her concern regarding the complexity of scientific cases and the pressure it puts on juries. A report in the New Scientist magazine went as far to suggest that the complex medical and scientific evidence presented baffled the juries in both trials. Forensic Toxicologist, Stuart Dickson, in the same article revealed that the Calder trials had created scepticism amongst the scientific community and that "there is certainly a feeling among scientists that there would be benefits to be had from an independent scientific body assessing the validity of the scientific arguments." However, on the contrary, defence lawyer Judith Ablett Kerr, was impressed by the juries in coping with the scientific evidence put forward to them. She gave insight into the presentation of the evidence by both counsels, suggesting that both teams utilised user-friendly graphs, charts and analogies and that the information presented was appropriate in aiding juries in the learning and understanding of complex scientific methodologies and evidence [1].

The way in which the complexity of the scientific evidence was dealt with in the Calder case heavily relied upon Tipping, as the judge, to play a 'gatekeeping' role, which required him to test scientific evidence for relevance and reliability. In his closing address in the first trial he provided legal guidance to the jury regarding the scientific evidence and stated that one of the trial's biggest issues concerned the prosecutions 'calendar effect' data and outlined the arguments the defence had produced to suggest that it could be invalid. He also pointed out the prosecutions failure to conduct the CEV test as a specific test for the positive identification of exposure to acrylamide and questioned why they had not done so. In the second trial he also issued advice of extreme caution to the new jury as they sorted their way through the conflicting evidence and opinions $[1,7]$.

The issue of expecting lay people to comprehend the complex and conflicting evidence put forward to them in the Calder trials stems from the approval of the admissibility of the evidence by Justice Tipping in the first instance. Aforementioned, technically the evidence gathered by the prosecution should never have been used in the courtroom as the novel approach undertaken to obtain this evidence was not accepted in the scientific community as a valid technique, nor had it been peer reviewed: it disobeyed the Daubert Principle. In utilising novel hair analysis methods, it was easy for the defence to point out potential downfalls and inconsistencies with the techniques. The trials essentially became a 'battle of the experts', whereby the unconventional technologies utilised were debated at length. Thus, it can be suggested that perhaps both juries were not baffled by the scientific evidence but were simply unconvinced by the scientific evidence offered to them [1,2].

It will continue to be unknown, whether or not the juries involved in the Calder trials were baffled or if they were unconvinced by the complex and contradictory evidence. Nevertheless, many suggestions were made after the second trial in order to improve and overcome the difficulties encountered by juries surrounding such complex scientific evidence. One suggestion was to adopt an independent body to assess the validity of the scientific arguments [1]. For example, in some fraud trials heard before judges, commercial law experts are called to sit alongside judges and guide their opinions. However adopting this approach for criminal t- 
rials would have vast implications. Another suggestion was to assemble juries of experts, a suggestion that few lawyers support $[1,2]$. Issues surrounding this notion include sourcing a large enough number of experts to form a scientific panel, experts would unavoidably know other scientist producing evidence and each may have conflicting agendas of their own. Thus, it is probably most appropriate to keep the composition of the jury as ordinary lay people and (with the legal guidance of the judge as the 'gatekeeper') for the experts to make comprehension of the evidence user-friendly.

\section{Acrylamide}

\section{Acrylamide Toxicokinetics}

Acrylamide toxicokinetics is concerned with how the body affects acrylamide upon exposure: many studies have been conducted in determining the absorption, distribution, metabolism and elimination of acrylamide and its mechanism of action. The most recent scientific understanding of acrylamide toxicokinetics is outlined below.

Firstly, it is to be noted that acrylamide is a small organic, water-soluble, vinyl monomer (classified as an alkene) that is highly reactive [8]. Acrylamide is what is referred to as a soft electrophile, meaning it is electron deficient and relatively polarisable, which allows it to form covalent bonds with soft, electron-rich (nucleophilic) residues on biological macromolecules, i.e. nucleic acids, proteins and/or enzymes [8]. Reactions of acrylamide with such biological molecules are not arbitrary, instead these interactions exhibit a significant degree of selectivity: toxic electrophiles will react selectively with biological targets of comparable softness. The unsaturated carbonyl structure of acrylamide preferentially forms adducts with the highly nucleophilic sulfhydryl thiolates on cysteine residues [8]. Additionally, adduct formation with lysine and histidine residues seem to occur predominantly at a higher dose range or in the final stage of chronic diseases where the saturation of the cysteine-thiolate population has been achieved.

Absorption: Exposure to acrylamide can occur dermally, by inhalation and by ingestion [9]. Most studies have focused on oral ingestion as the route of administration: little research has described events surrounding acrylamide inhalation, for example. This is because the half-life of acrylamide in open air is relatively short compared to its other potential modes of transportation into the body. It has been established the gastrointestinal tract readily absorbs acrylamide [10]. Another site susceptible to acrylamide absorption is nervous tissue of the peripheral nervous system.

Distribution: Distribution of acrylamide varies upon the route of administration (i.e. orally, intravenously or dermally). The distribution is also affected by the acrylamide variant that is introduced into a biological system: either acrylamide monomer or polyacrylamide. Typically, acrylamide is rapidly absorbed from most sites of exposure and is then evenly distributed among tissues [11]. Additionally, acrylamide can cross the placenta and reach the foetus and is transferred to breast milk [12].

Metabolism: Acrylamide is metabolised in the liver by two main pathways; inactivation by glutathione conjugation or bioactivation through epoxidation to glycidamide catalysed by cytochrome P450 2E1 [12]. The extent of glycidamide formation is dose and route dependent and it is highest for low-dose dietary acrylamide exposure [11]. Both acrylamide and glycidamide bind in vivo with cellular nucleophiles: acrylamide forms adducts with proteins and glycidamide forms adducts with proteins and DNA. In humans N-acetyl-S-(2-carbamoylethyl)-cysteine (a mercapturic acid) has been identified as the major metabolite of acrylamide. Another mercapturic acid that is formed via glycidamide-glutathione conjugation is $\mathrm{N}$-acetyl-S(2-hydroxy-2-carbamoylethyl) cysteine. In addition to mercapturic acid adducts, haemoglobin adducts are also formed; acrylamide and haemoglobin form $\mathrm{N}$-(2carbamoylethyl) valine and glycidamide and haemoglobin form N-(2-hydroxy-carbamoylethyl) valine [13] (Figure 1).

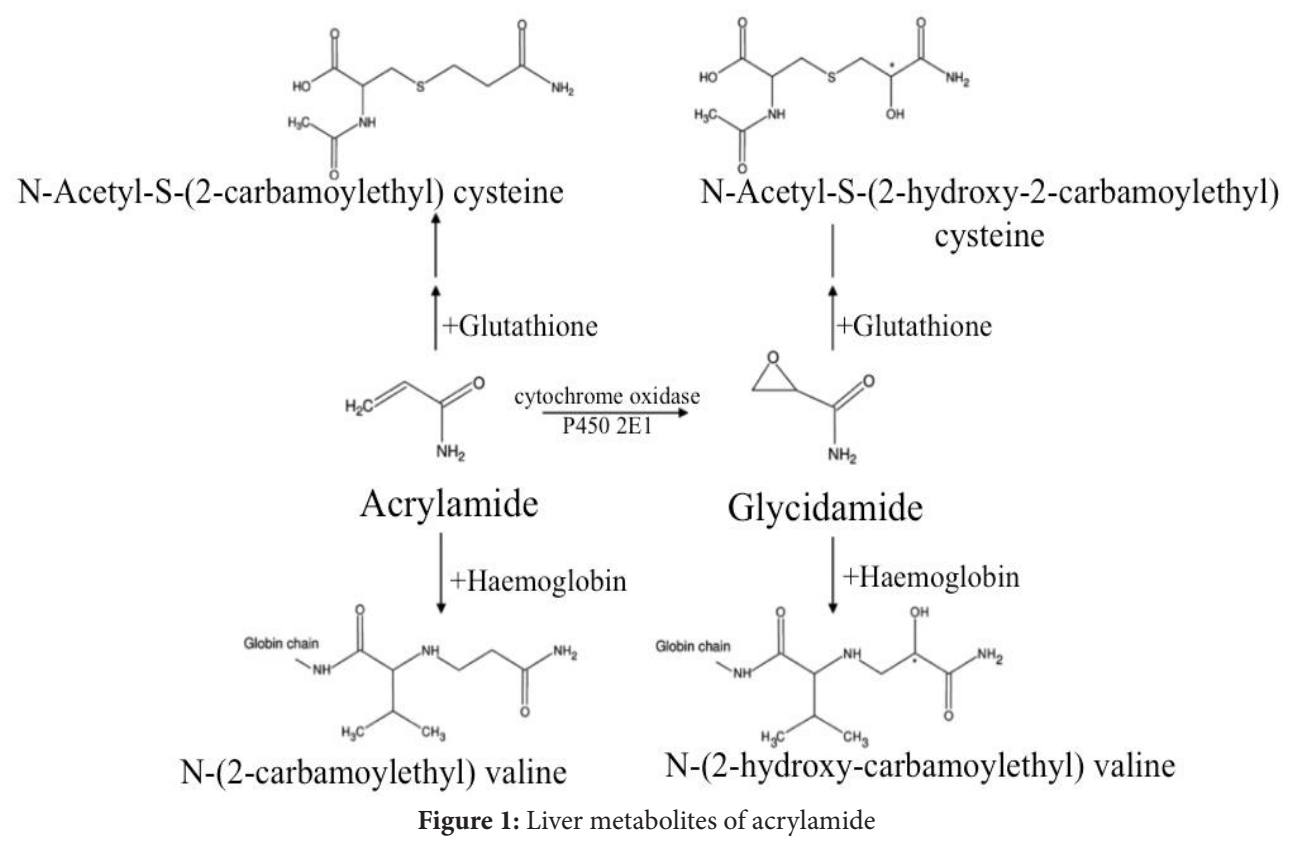


Elimination: Free acrylamide is excreted approximately 24 hours after absorption. Its major metabolite, N-acetyl-S-(2carbamoylethyl)-cysteine, is a urinary mercapturic acid that is excreted in the urine and can be utilised as a biomarker to the exposure of acrylamide up to 48 hours after exposure [1,11-13].

Biomarkers of Acrylamide Exposure: Acrylamide and glycidamide are not useful biomarkers in themselves: they are both reactive compounds and only have half-lives in the human body of 4.6 and 1.9 hours respectively [13]. Urinary mercapturic acids have a half-life of approximately 3.5 hours, so they are basically no more useful than acrylamide or glycidamide as a biomarker. DNA adducts have a longer half-life of about 4 days, but have only been researched in animals. Haemoglobin adducts, however, are the most useful, since they are stable and reside as an adduct for the life time of the red blood cell it is attached to, which is approximately 120 days in humans [14].

\section{Acrylamide Toxicodynamics}

Acrylamide toxicodynamics is concerned with how acrylamide affects the body. Acrylamide has shown to be a genotoxic carcinogen. It has also been implicated in neurotoxicity; however, these effects are still highly debatable.

Acute exposure to acrylamide leads to ataxia, tremor, amentia, as well as speech and reflex disturbance. Animal tests have shown to develop neuropathies, tremor, impaired coordination, motor dysfunctions, neuromuscular weakness and reduced nerve conduction velocity. After a single administration of acrylamide at higher concentrations, tremor, ataxia, convulsion, muscle weakness, circulation collapse as well as body weight loss were observed in rats, mice, guinea pigs, rabbits and cats [15].

The cellular toxicity of acrylamide at high concentrations is due to the depletion of cellular glutathione [13]. Moreover the irreversible formation of adducts with thiolate groups of cysteine residues can lead to modulation of various signal transduction pathways (i.e. they can trigger apoptosis, interact with the tumour suppressor gene and interact with certain DNA repair enzymes). Acrylamide's genotoxicity is also related to its carcinogenicity. Acrylamide is categorised to be a likely carcinogen to humans. Long-term rat studies have observed an enhanced occurrence of certain tumours following daily administration of acrylamide [16].

Neurotoxicity has demonstrated to be evident when acrylamide and glycidamide react with proteins that are involved in axonal transport, leading to the inhibition of axonal transport and inhibition of neurotransmitter uptake. Additionally time-dependent depletion of glutathione in the neurons is thought to contribute to the neurotoxic effect of acrylamide. Dopamine release, uptake and storage is also affected, which correlates to the decrease in free sulfhydryl groups (acrylamide forms adducts with sulfhydryl groups of presynaptic proteins) [16].

\section{Sources of Acrylamide}

Acrylamide is used for the synthesis of a variety of polyacrylamide products for industrial, agricultural and medical applications. For example, polyacrylamide preparations are utilised in the cosmetic, paper and textile industries, in ore processing, medical research in gel electrophoresis, soil conditioners, as flocculants for wastewater treatment and is found in thermally treated food products - to name a few. However, there are additional sources with the potential for daily acrylamide exposure, which will be discussed below [16].

Breathing Air: The occurrence of acrylamide in the atmosphere has not been extensively analysed. Normally, no significant entry of acrylamide from environmental pollution into the atmosphere occurs. No natural sources of acrylamide have been identified, however man-made structures have in the past resulted in release of acrylamide into the environment. For example a chemical grout containing acrylamide was used during tunnel construction in Sweden, as a result of incorrect usage high amounts of acrylamide were released into the environment [16].

Food: Various mechanisms of acrylamide formation in food have been explored. The most important mechanism for acrylamide formation appears to be the reaction of reducing carbohydrates with amino acids (particularly asparagine) during non-enzymatic browning. Thus acrylamide is mainly formed in carbohydrate-rich, strongly heated foods, such as french fries, potato chips/crisps and coffee [16].

The major foods contributing to dietary acrylamide exposure in New Zealand (in 2012) [17] were potato products, bread, breakfast cereals and beverages (consistent with international findings). These studies conducted found the mean acrylamide concentrations for potato crisps to be $581 \mu \mathrm{g} / \mathrm{kg}$. This number was significantly higher in 2006 at $1570 \mu \mathrm{g} / \mathrm{kg}$. Acrylamide concentrations in potato hot chips and wheat biscuit cereals were recorded at $270 \mu \mathrm{g} / \mathrm{kg}$ in 2006 . Overall mean estimates of dietary acrylamide exposure in 2012 were determined to be between 0.72 and $1.04 \mu \mathrm{g} / \mathrm{kg}$ body weight/day for adults in New Zealand.

Tobacco Smoke: Tobacco smoke is a large source of exposure to acrylamide. Heavy smokers, categorised as smoking approximately 20 cigarettes/day, may inhale up to $40 \mu \mathrm{g}$ acrylamide/day through tobacco smoke alone. This may contribute to the occurrence of acrylamide in breathing air [16]. 


\section{Other Issues in the Calder Case}

\section{Law Enforcement Bias}

Martin Sage, a forensic pathologist at the School of Medicine at Canterbury University was contacted by Lloyd's doctors around the time he was admitted to hospital, after results for tests for likely diseases returned negative. Sage concluded that bacterial or viral infections could not be ruled out (without a brain autopsy) however they seemed unlikely causes of the symptoms. It was Sage who was the first to suggest that Lloyd may have been poisoned [1]. When Detective Sergeant Rob Pope became involved, he initially had samples of Lloyd's hair tested for the 'usual' heavy metal suspects; arsenic, mercury, tin and thallium. These tests returned nothing. Sage happened to come across reports of accidental exposure to acrylamide monomer in industry, in scientific literature. He believed that Lloyd's symptoms were consistent with descriptions in the reports. From then on their attention focussed solely on acrylamide [1]. It is known that acrylonitrile, a similar substance to acrylamide, can produce adducts such as the haemoglobin adduct at the N-terminal valine (the adduct is seen with acrylamide exposure) [16].

\section{Scientific Expert Misinterpretation of Evidence}

It was suggested by one of the defence's many scientific experts, Maurice Owen, that the 'calendar' effect CEC graph followed the pattern of an infection $[1,2]$. As the prosecution was focussed on finding a poison, the potential for misinterpreting the data presented or disregarding information that may alternatively explain the evidence was high. Previous studies have in fact shown that advanced glycation end products (i.e. CEC) are formed by modification of free cysteine sulfhydryl groups of proteins by aldehydes in some disease processes, diabetes for example [18]. Neurotoxic effects have also been associated with acrylonitrile exposure [1]. Thus this disregard for considering the evidence as a whole and it's possible various interpretations may have lead to a miscarriage of justice, in convicting Calder of the alleged attempted murder of Lloyd.

\section{Conclusions}

i)Both trials in the Calder case heavily relied upon the small amount of chemical evidence and scientific expertise available, since the case was largely built on circumstantial evidence.

ii) In the first trial, the technique that was adopted (hair analysis for CEC) for the determination of acrylamide exposure was novel: it had not been shown to be a reliable, nor scientifically validated method. According to the first principle of the Daubert standard, expert testimony may be considered admissible when the theory or technique can be and has been tested. Justice Tipping, in making a decision to allow the presentation of the evidence deduced from this novel method, broke this first principle and thus violated the Daubert principle. Technically, the failure of the forensic scientists to use a rigorous scientific procedure meant that evidence should have never been considered to be admissible in court.

iii)Hair analysis nowadays, is still a highly controversial source of evidence and it is considered that hair analysis should not be regarded as an ultimate substitute for traditional specimens (blood and urine), but instead it should act as a source for complimentary and informational evidence, primarily for the following reasons. Firstly, it is not possible to calculate blood or plasma concentrations based on hair results; just because there was an apparent high concentration of CEC in Lloyd's hair samples (>500 micrograms of CEC per gram of hair), doesn't mean this corresponded to a high concentration of the metabolite in the blood. Secondly, these are still (as of 2014) a lack of standardisation for sampling, and extraction and decontamination techniques. This does not allow for general consensus or uniformity regarding hair analysis protocol, which is essential for the admissibility of forensic evidence. It can be suggested that such protocols need to be developed so that hair analysis can be effectively submitted as evidence, since there are a number of benefits associated with hair as a biological specimen.

iv)It will continue to be unknown whether or not the juries involved in both the Calder trials were baffled or simply unconvinced by the complex and contradictory scientific evidence presented to them. If the jury did not, in fact, understand the conflicting information that was offered, this would have had a profound effect on the verdict. Thus, it is important for the judge to continue to play a gatekeeping role in providing legal guidance regarding scientific evidence for juries of lay people.

v)A single standardised method for the detection of acrylamide exposure is still not established. Additionally, a definitive biomarker to pinpoint acrylamide exposure is not agreed upon in scientific literature. It appears that, according to present studies, the detection for acrylamide exposure should have utilised the identification a number of biomarkers across a number of specimens. It has been concluded that hair analysis should have never been used for scientific evidence. Alternatively, the detection of the two haemoglobin adducts ( $\mathrm{N}$-(2-carbamotlethyl) valine (CEV) and $\mathrm{N}$-(2-hydroxy-carbamoylethyl) valine) should have been the first metabolites considered for analysis as the metabolic footprint of exposure to acrylamide. Additionally, the analysis of the two mercapturic acids (N-acetyl-S-(2-carbamoylethyl)-cysteine and $\mathrm{N}$-acetyl-S(2-hydroxy-2-carbamoylethyl) cysteine) , in a urine sample that should have been taken from Lloyd around the time he became ill, should have been analysed for. Finally, the defence's argument in the second trial that ultimately discredited the CEV test as evidence - that being that the positive identification of glycidamide in the liver was more specific for acrylamide exposure - was partially incorrect. As discussed, glycidamide is excreted from the body almost as readily as acrylamide and is not very useful as a biomarker: the detection of glycidamide would have been impossible with the samples available. Thus, the prosecution was right in doing a test for CEV in the blood in the second trial and the evidence possibly should have had more emphasis put on it's significance. 
vi)Acute exposure to acrylamide leads to ataxia, tremor, amentia as well as speech and reflex disturbance - all symptoms of which were displayed by Lloyd. However, it has also been demonstrated that acrylonitrile can elicit the neurotoxic effects as seen in Lloyd's instance. Additionally, similar metabolites to acrylamide are formed in biological systems upon exposure to acrylonitrile. Overall, it is possible that law enforcement bias, by focussing their attention solely on acrylamide, and potential scientific expert misinterpretation of evidence may have formed their conclusion of acrylamide administration, without the consideration of other possibilities (i.e. acrylonitrile exposure or a disease process).

vii)In the eyes of the law, Vicky Calder is innocent. Unfortunately (for the prosecution) the case was riddled with difficulties from the very start. Hair analysis wasn't - and still isn't - a reliable technique for the gathering of forensic evidence, the evidence presented became very complex and contradictory and had the potential to confuse the juries of lay people in both trials and a biomarker for acrylamide exposure is still not agreed upon. Overall there was little possibility that the court was going to produce a guilty verdict for these reasons: Calder was always going to be acquitted.

\section{References}

1. Goulter J (1997) No Verdict. A Thousand Million Pieces: The Puzzle of Professor Lloyd. Random House, New Zealand.

2. New Scientist Magazine (1996, May) The Calder-Lloyd Case. New Scientist Magazine 2031.

3. Barroso M and Gallardo E (2014) Hair analysis for forensic application: is the future bright? Bioanalysis 6: 1-3.

4. Kintz P (2004) Value of hair analysis in post-mortem toxicology. Forensic Sci Int 142: 127-34.

5. Vincenti M, Salomone A, Gerace E and Pirro V (2013) Application of Mass Spectrometry to Hair Analysis for Forensic Toxicological Investigations. Mass Spectrom Rev 32: 312-32.

6. Ditton J (2002) Technical Review. Hair Testing: Just how accurate is it? Surveillance \& Society 1: 86-101.

7. Belt K (1998) Novel Scientific Evidence and Judicial Gatekeeping: R v Calder and Daubert v Merrell Dow Pharmaceuticals Compared. Victoria University of Wellington Law Review 14.

8. LoPachin RM, Gavin T (2012) Molecular Mechanism of Acrylamide Neurotoxicity: Lessons Learned from Organic Chemistry. Environ Health Perspect 120: 1650.

9. Fennell TR, Sumner SC, Snyder RW, Burgess J, Spicer R, et al. (2005) Metabolism and Haemoglobin Adduct Formation of Acrylamide in Humans. Toxicological Sciences 85: 447-59.

10. Zodl B, Schmid D, Wassler G, Gundacker C, Leibetseder T, et al. (2007) Intestinal transport and metabolism of acrylamide. Toxicology 232: 99-108.

11. Bjellaas T, Olesen PT, Frandsen H, Haugen M, Stølen LH, et al. (2007) Comparison of Estimated Dietary Intake of Acrylamide with Haemoglobin Adducts of Acrylamide and Glycidamide. Toxicol Sci 98: 110-7.

12. Kopp EK, Dekant W (2009) Toxicokinetics of acrylamide in rats and humans following single oral administration of low doses. Toxicol Appl Pharmacol 235: $135-42$.

13. Bader M (2012) N-(2-Carbamoylethyl)valine-haemoglobin adduct of acrylamide. Biomonitoring Methods: The MAK Collection for Occupational Health and Safety 12: 145-67.

14. Alexander J (2008) Biomarkers of Acrylamide. Norwegian Institute of Public Health, EFSA Colloquium on Acrylamide.

15. LoPachin RM (2004) The Changing View of Acrylamide Neurotoxicity. Neurotoxicology 25: 617-30.

16. Guth S, Habermeyer M, Baum M, Steinberg P, Lampen A, et al. (2013) Thermally induced process-related contaminants: The example of acrolein and the comparison with acrylamide. Mol Nutr Food Res 57: 2269-82.

17. Cressey P, Thomson B, Ashworth M, Grounds P and McGill E (2012) Acrylamide in New Zealand food and updated exposure assessment. Ministry of Agriculture and Forestry, Wellington.

18. Mostafa AA, Randell EW, Vasdev SC, Gill VD, Han Y, et al. (2007) Plasma protein advances glycation end products, carboxymethyl cysteine, and carboxyethyl cysteine, are elevated and related in patients with diabetes. Mol Cell Biochem 302: 35-42.

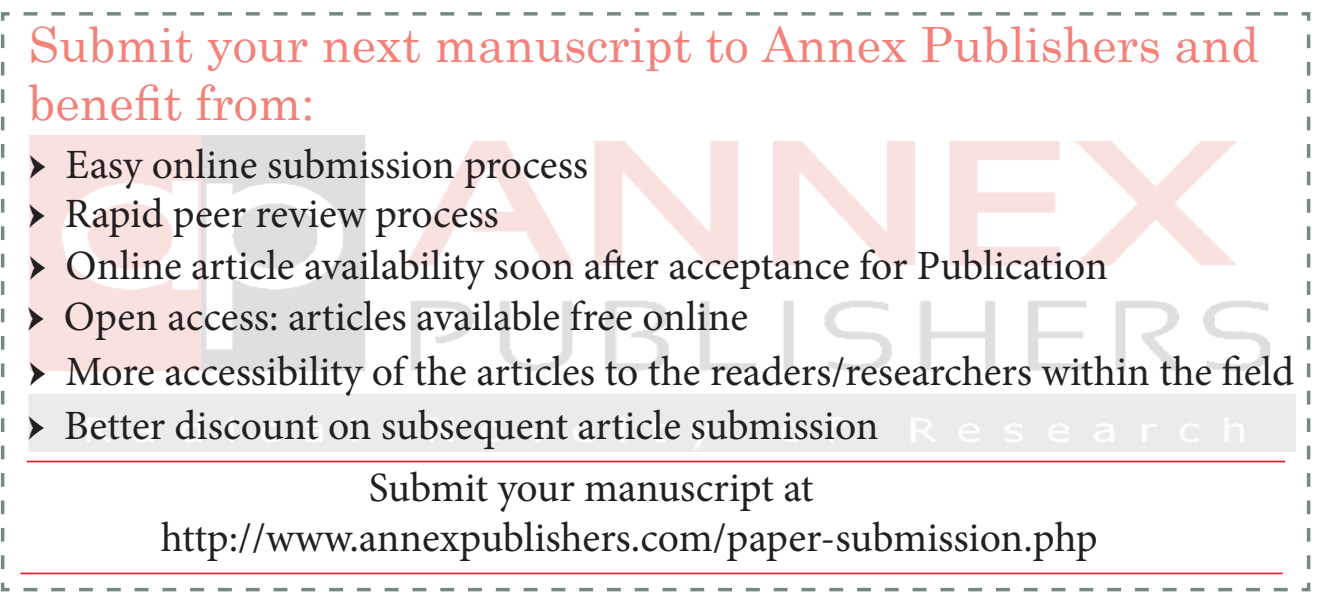

